\title{
European Teleradiology now and in the future: results of an online survey
}

\author{
E. R. Ranschaert • F. H. Barneveld Binkhuysen
}

Received: 7 June 2012 /Revised: 14 October 2012 / Accepted: 16 November 2012 /Published online: 18 December 2012

(C) The Author(s) 2012. This article is published with open access at Springerlink.com

\begin{abstract}
Objectives To obtain an overview of teleradiology usage within Europe, to evaluate the current opinion and future vision about this technique.

Methods A web-based survey targeted at active radiologists throughout Europe.

Results A total of 368 radiology professionals participated in the survey. Among them $65 \%$ currently use teleradiology. The main usages are in-house image distribution $(71 \%)$ and on-call readings from home (44\%). The major advantages are improved collaboration with other radiologists (46\%) and efficient distribution of workload (38\%). Outsourcing is performed by $35 \%$ of the participants, among them $68 \%$ use commercial services. The major advantages of outsourcing are availability of second opinions $(82 \%)$ and additional capacity for on-call services $(71 \%)$. The major disadvantages are insufficient integration of patient history and priors (69\%), and limited communication with clinicians $(68 \%)$. The majority expressed a positive opinion regarding the future of teleradiology $(80 \%)$ predicting a growing importance (46\%). Opportunities ought to be found in emergency reading services, flexible support of small practices and in collaborative platforms.

Conclusions A wide usage of teleradiology throughout Europe is perceived; however usage of commercial services is relatively limited. Regarding cross-border services, there
\end{abstract}

\section{E. R. Ranschaert $(\varangle)$}

Department of Radiology, Jeroen Bosch Ziekenhuis,

Postbus 90153,

5200 ME 's-Hertogenbosch, Netherlands

e-mail: e.ranschaert@telenet.be

F. H. B. Binkhuysen

Soester Hoogt 4,

3768 MK Soest, Netherlands

e-mail: fbb@imatel.nl is a great demand for a focused Pan-European legislation, an adapted price regulation and a quality assurance framework.

Main Messages

- A wide variety of teleradiology applications exist in Europe

- Implementation mainly occurs in countries with a high concentration of networked PACS

- Usage of commercial teleradiology services in Europe is relatively limited

- Language is an unsolved issue and limiting factor for further deployment of services

- There is a demand for a Pan-European legislation, price regulation and quality assurance framework

Keywords Teleradiology $\cdot$ Radiologists $\cdot$ European community $\cdot$ Outsourcing $\cdot$ Future

\section{Introduction}

Teleradiology is defined as the electronic transmission of radiographic images between two geographical locations for the purposes of interpretation and consultation [1-3]. For several years picture archiving and communication systems (PACS) have been widely implemented in Europe. PACS combined with the overall presence of high-bandwidth Internet connections has facilitated the transmission of medical images between different locations for diagnostic purposes. However, the availability of PACS in hospitals throughout Europe is still unevenly distributed, with the majority being used in the Nordic countries, UK, Netherlands and Belgium [4]. Currently, technical problems regarding the electronic transmission of large image data sets have essentially been solved. However the main challenge is seamless integration of teleradiology with PACS, in order to enable flexible exchange of patient related information, i.e. 
electronic patient records (EPR) and radiological images including priors $[2,5,6]$.

In several European countries, teleradiology has become part of the regular workflow for purposes of workload balancing. This is usually the case within a hospital comprised of several facilities, separated geographically. In countries with PACS integrated in a regional or national network, image distribution can be organised in a cross-enterprise fashion [3]. In other institutions, teleradiology is used for providing remote, off-hour radiological coverage; for emergency readings and to a lesser extent for subspecialty readings [5]. In the past decade, several national and international commercial teleradiology providers have emerged in Europe, facilitating the outsourcing of diagnostic readings $[3,7,8]$.

Different models for the usage of teleradiology can be defined accordingly: (1) a single facility (hospital or imaging centre) using teleradiology for on-call purposes (home-based radiologists); for obtaining expert/second opinions; or for outsourcing the readings to an outside teleradiology company or hospital, (2) an enterprise with multiple facilities, using teleradiology for in-house distribution of workload, for obtaining second/expert opinions or for outsourcing the work to a commercial teleradiology provider, (3) a radiology group or teleradiology company providing professional services to several related or unrelated facilities (in terms of ownership) $[2,6]$.

The objective of this study was to obtain an overview of the current usage of teleradiology in its various forms, throughout Europe, and to evaluate the current opinion and future vision about this technique. Analysis of the results is aimed at providing information that can be used in future discussions about the further usage and deployment of teleradiology services in Europe.

\section{Materials and methods}

An online electronic survey was created using the SurveyMonkey web-based survey tool [9]. The survey consisted of 32 multiple-choice questions and three open questions. Data collected from the multiple-choice questions included information on demographics, types of services used, security of data transmission, communication of reports, quality assurance and legal regulations (Table 1). Additional data were obtained regarding the advantages, disadvantages, threats and opportunities of teleradiology services. The open questions offered the participants an opportunity to express their opinions regarding the current and future role of teleradiology. The target subjects for the survey were radiologists, radiology residents and radiology managers, professionally active in a European country. The survey was created using the advanced logic features provided by SurveyMonkey, for directing participants to the relevant questions while excluding participants outside of the target group. The survey was
Table 1 Subject categories of the questions in the survey

Question categories
1. Demographical data
2. Types of teleradiology
3. Types of examinations
4. Technical issues
5. Security issues (patient data, additional information)
6. Communication of results
7. Advantages/disadvantages
8. Threats and opportunities
9. Quality assurance
10. Future of teleradiology

published online with collaboration of the European Society of Radiologist (ESR). All ESR members were encouraged to participate in the survey, through announcements and personal email invitations via online social media platforms such as: the ESR internet site, the ESR Facebook page, and also via Twitter and LinkedIn [10-13]. A brief article was published in the ESR Science Report [37] and electronically distributed to all ESR members. Finally some publicity was made during the Management in Radiology (MIR) 2011 Scientific Meeting (Sept. 29-30, Nice, France) and the Dutch Radiology Days (Sept. 29-30, Maastricht, The Netherlands). The survey remained online between September 14th and October 10th. For analysis of the quantitative data, the SurveyMonkey statistical tools and SPSS statistical software (SPSS Statistics 20, IBM Corporation, NY, USA) were used. In the open question, all participants were able to freely enter ideas with regard to their future vision of teleradiology. These suggestions were isolated from the quantitative results. Subjects and themes were identified, examined, ordered, counted, compared and analysed following the thematic coding technique as described by Uwe Flick [14].

\section{Results}

Demographics

A total of 368 radiology professionals participated in the survey: radiologists $(71 \%)$, residents $(14 \%)$ and radiology managers $(6 \%)$. The participants represented 35 European countries, the largest groups were from Austria (22\%) and Belgium (22\%) followed by the UK (7\%), Netherlands (6\%), Germany (5\%), Italy (4\%), Estonia (4\%), Spain (4\%), France (3\%), Greece (3\%) and Sweden (3\%).

The locations of the main professional activities of the respondents are: public or private hospitals (55\%), university hospitals $(36 \%)$, or a private practice or private medical 
centre $(24 \%)$ (Table 2$)$. All the respondents work within a group of radiologists: the majority in a small group of 2-10 (41\%); others in larger groups between 10 and $20(22 \%)$ or over $20(30 \%)$.

\section{Types of teleradiology}

A large majority of respondents (65\%) is currently using teleradiology. As for those not using teleradiology yet, $36 \%$ plan on using it in the near future and $46 \%$ are still in doubt. A minority (18\%) do not use this technique, nor plan to do so in the future; the main reasons being the absence of a necessity for this type of service (42\%) or a lack of financial means $(23 \%)$. The current usage forms of teleradiology are summarised in Tables 3 and 4. It appears that distribution of images within the same institution is the most frequently used form of teleradiology (71 \%) followed by night-time and weekend readings from home (44\%). When asking specifically if the participants use teleradiology to outsource images, $35 \%$ confirm to do so. The most frequent reason chosen is to obtain second/expert opinions (41\%) or for night coverage (40\%). In $19 \%$ of the cases, teleradiology outsourcing is used in order to solve temporary capacity problems (i.e. staff shortages, holidays and illness). Images are then preferably sent to a teleradiology company or private practice $(52 \%)$, academic centre $(32 \%)$ or other networked hospital (8\%). A commercial provider in another country is consulted in $15 \%$ of the cases, only $2 \%$ of which is located outside Europe. Some less frequent applications of teleradiology are: research purposes, off-site (home) reporting during the daytime and transmission of images to a tertiary centre (each $0.5 \%$ ). When outsourcing is used, routine crosssectional examinations are sent most frequently (57\%), followed by CR studies (32\%) and emergency readings (31\%).

Several respondents are providers of teleradiology services, whether on a non-commercial (32\%) or commercial (26\%) basis. These services consist mostly of primary

Table 2 Location of main professional activity of the respondents

\begin{tabular}{lcc}
\multicolumn{2}{l}{ Location of main professional activity } & \\
\hline & Percentage & Number \\
\hline Public hospital & $38 \%$ & 122 \\
University hospital & $36 \%$ & 115 \\
Private hospital & $17 \%$ & 56 \\
Private practice & $13 \%$ & 41 \\
Private medical or & $11 \%$ & 34 \\
$\quad$ diagnostic centre & $5 \%$ & 16 \\
Teleradiology company & $3 \%$ & 8 \\
Research institute & $1 \%$ & 3 \\
Other & & \\
\hline
\end{tabular}

Table 3 The current usage of teleradiology

How do you use teleradiology?

\begin{tabular}{|c|c|c|}
\hline & Percentage & Number \\
\hline $\begin{array}{l}\text { Within hospital (cross-enterprise } \\
\text { work list sharing) }\end{array}$ & $71 \%$ & 144 \\
\hline At home when on call & $44 \%$ & 90 \\
\hline Other & $20 \%$ & 40 \\
\hline answered question & & 203 \\
\hline skipped question & & 167 \\
\hline
\end{tabular}

(77\%) and subspecialty readings (51\%). The examinations are sent from other hospitals within the same country (87\%), most often associated hospitals or hospitals within the same region. Image analysis for pharmaceutical trials (research) and medico-legal expertise cases are performed by $10 \%$ of the radiologists who provide reading services.

\section{Technical issues}

Following analysis of the technically oriented questions, it appears that DICOM is by far the preferred image format (92\%). The majority of respondents use a VPN-type of Internet connection (42\%), in most other cases a hospitalwide or regional network connection is used for image transmission (37\%). Worthy of mentioning, in Germany the accepted standard for teleradiology is DICOM-email [15]. Clinical records and other relevant patient information are usually obtained through direct connection with the PACS/radiology information system (RIS) (54\%), while this information is also obtained via telephone (30\%) and fax $24 \%$. Only a minority of respondents (16\%) use a dedicated teleradiology platform. An electronic patient record (EPR) is accessible in $26 \%$ of the cases. In many situations additional information is obtained directly from the hospital information system (HIS) $(51 \%)$. The most frequent method for communicating the results or reports is via telephone $(79 \%)$. In $43 \%$ of the cases, reports are

Table 4 Reasons for outsourcing radiological examinations

Why do you outsource radiological examinations?

\begin{tabular}{llc}
\hline & Percentage & Number \\
\hline As part of regular workflow & $49 \%$ & 33 \\
For a second or expert opinion & $41 \%$ & 28 \\
When on call (nights) & $40 \%$ & 27 \\
On a temporary basis (i.e. capacity & $19 \%$ & 13 \\
$\quad$ problems) & $6 \%$ & 4 \\
Other & & 68 \\
answered question & & 302 \\
skipped question & &
\end{tabular}


automatically incorporated in the RIS and $37 \%$ use email for transmitting the results.

The main reasons for non-usage of teleradiology are lack of financial means $(23 \%)$ and technical difficulties related to implementation on an organisational level (21\%), or absence of PACS (9\%). Other factors affecting the non-usage of teleradiology regard personal issues among: radiologists (18\%), hospital managers $(13 \%)$ and clinicians $(6 \%)$.

\section{Advantages and disadvantages}

Table 5 summarises the opinions regarding the advantages of teleradiology in general. The majority agrees/strongly agrees that the possibility for collaboration is the most valuable aspect $(74 \%)$, followed by the ability to more efficiently distribute the workload $(70 \%)$. The main advantages of outsourcing with teleradiology are the possibility to receive second opinion/subspecialty advice ( $82 \%$ ) and a greater availability of radiologists for on-call services (72\%). The main disadvantage of outsourcing by teleradiology is the insufficient integration of patient history and/or previous studies (69\%), while limited communication with clinicians seems to be the second greatest drawback (68\%). Additional disadvantages are outlined in Table 6.

\section{Threats and dangers}

The main threats and dangers perceived due to teleradiology outsourcing, as summarised in Table 7, are: the fear of losing control over the business $(61 \%)$, the fear of reducing the quality of reports $(54 \%)$, creation of instability in the job market and in radiologists' income (49\%). Forty-eight percent perceive teleradiology outsourcing as a threat to providing good patient care.

\section{Quality assurance}

According to a large majority, the quality of teleradiology services could be improved by developing an obligatory quality assurance system (78 \%). Quality could be improved by various solutions, among them the implementation of a specific teleradiology training programme $(70 \%)$, or an obligatory double reading system (57\%).

\section{Cross-border teleradiology}

Regarding cross-border teleradiology, $65 \%$ agree that panEuropean image distribution and sharing should be allowed under specific regulations; however, a small majority of participants who addressed this topic in the open question expressed the opinion that cross-border teleradiology has no future $(3.26 \%$ no versus $2.17 \%$ yes). An adapted reimbursement regulation for cross border teleradiology activities should be agreed upon within European countries or among health insurance companies, according to $60 \%$ of the respondents.

\section{Future of teleradiology (open question)}

In an open question, the participants were asked if they could describe how they see the future of teleradiology, and if they thought that its importance would grow or, rather, decline. A large majority expressed a positive to strongly positive vision regarding the future of teleradiology (80\%). Almost half of the 235 participants replying to this question foresee a growth in the importance of teleradiology (46\%). The need for further standardisation and better regulation of the financial and legal aspects, were issues expressed by $20 \%$ of the respondents. According to the participants, the shortage of radiologists and the need for sub-specialisation are the principal reasons for the continued need for teleradiology in the future; economic reasons are regarded as having less importance. The fear for a possible reduction of work value is regarded as the most negative consequence of teleradiology. This feeling is well expressed by the following statement by one of the participants: "Radiologists will become battery hens merely reporting in isolation for money instead of giving added value as doctors

Table 5 Advantages of teleradiology in general (the highest percentages are in bold)

\begin{tabular}{|c|c|c|c|c|c|c|c|}
\hline Answer options & $\begin{array}{l}\text { Strongly } \\
\text { disagree }\end{array}$ & Disagree & Neutral & Agree & $\begin{array}{l}\text { Strongly } \\
\text { agree }\end{array}$ & $\begin{array}{l}\text { No } \\
\text { opinion }\end{array}$ & $\begin{array}{l}\text { Rating } \\
\text { average }\end{array}$ \\
\hline $\begin{array}{l}\text { Possibility to discuss cases in a collaborative } \\
\text { network }\end{array}$ & $4 \%$ & $7 \%$ & $12 \%$ & $46 \%$ & $28 \%$ & $2 \%$ & 3.90 \\
\hline $\begin{array}{l}\text { Greater efficiency and improved radiological } \\
\text { services }\end{array}$ & $3 \%$ & $10 \%$ & $16 \%$ & $38 \%$ & $32 \%$ & $1 \%$ & 3.86 \\
\hline $\begin{array}{l}\text { Better distribution of the workload throughout the } \\
\text { organisation }\end{array}$ & $4 \%$ & $6 \%$ & $24 \%$ & $38 \%$ & $27 \%$ & $2 \%$ & 3.80 \\
\hline Ability to sub-specialise & $3 \%$ & $10 \%$ & $19 \%$ & $37 \%$ & $27 \%$ & $4 \%$ & 3.78 \\
\hline Improved communication with referring clinicians & $11 \%$ & $19 \%$ & $22 \%$ & $28 \%$ & $18 \%$ & $2 \%$ & 3.23 \\
\hline Profession is now more attractive for newcomers & $10 \%$ & $16 \%$ & $32 \%$ & $25 \%$ & $13 \%$ & $5 \%$ & 3.15 \\
\hline
\end{tabular}


Table 6 Disadvantages of teleradiology outsourcing (the highest percentages are in bold)

\begin{tabular}{|c|c|c|c|c|c|c|c|}
\hline Answer options & $\begin{array}{l}\text { Strongly } \\
\text { disagree }\end{array}$ & Disagree & Neutral & Agree & $\begin{array}{l}\text { Strongly } \\
\text { agree }\end{array}$ & $\begin{array}{l}\text { No } \\
\text { opinion }\end{array}$ & $\begin{array}{l}\text { Rating } \\
\text { average }\end{array}$ \\
\hline $\begin{array}{l}\text { Insufficient integration of patient history/ } \\
\text { previous studies }\end{array}$ & $0.4 \%$ & $16 \%$ & $11 \%$ & $40 \%$ & $29 \%$ & $4 \%$ & 3.84 \\
\hline $\begin{array}{l}\text { Insufficient communication with referring } \\
\text { clinicians }\end{array}$ & $2 \%$ & $13 \%$ & $13 \%$ & $37 \%$ & $31 \%$ & $4 \%$ & 3.84 \\
\hline Too impersonal, no contact with radiologist & $2 \%$ & $19 \%$ & $22 \%$ & $30 \%$ & $25 \%$ & $2 \%$ & 3.58 \\
\hline Insufficient quality assessment & $6 \%$ & $19 \%$ & $28 \%$ & $28 \%$ & $16 \%$ & $4 \%$ & 3.32 \\
\hline Involves complex logistics & $4 \%$ & $24 \%$ & $30 \%$ & $29 \%$ & $9 \%$ & $4 \%$ & 3.16 \\
\hline Technology is too unstable/insecure & $10 \%$ & $38 \%$ & $27 \%$ & $12 \%$ & $7 \%$ & $7 \%$ & 2.66 \\
\hline
\end{tabular}

giving a medical opinion on cases to their clinical colleagues". From the qualitative analysis, it also appears that there is a great demand for second/expert opinions and this feature is regarded as one of the most attractive and promising aspects of teleradiology. Further implementation of platforms/facilities facilitating collaboration between radiologists was repeatedly mentioned as having great potential. Moreover, provision of emergency reading services and flexible support to small practices is mentioned as one of the most promising opportunities for increasing teleradiology importance in the future. Only a small majority predicts that cross-border teleradiology has no future.

\section{Discussion}

\section{Current situation}

According to our survey result analysis, it is clearly apparent that teleradiology is currently being used for a wide spectrum of purposes in Europe. The most common usage is inhouse (intra-organisational or intra-institutional) distribution of imaging studies, as a tool for efficient workload sharing between the different locations of the same organisation
(71 \%). The second most popular application is on-call (preliminary) emergency readings from home (44\%). A relatively small portion $(10 \%)$ of the total number of participants is outsourcing images externally (transmission of images outside the organisation) to obtain second/expert opinions and to cover readings beyond office-time. In this subgroup of external outsourcing, a small number of studies are sent to commercial providers $(15 \%)$, one-fifth of which is even located in a different country (not defined in which continent). Similar findings were reported in the results of a Swiss teleradiology survey organised in 2004 [16]. In the Swiss survey, the participants were requested to predict the future purposes for teleradiology. The Swiss radiologists rated the most important purposes for future teleradiology would be the (intra-organisational) distribution of imaging studies and the emergency readings followed by expert consultations and education. Whereas in Europe most of the teleradiology activity is in-house, in the United States more than half of radiology practices are outsourcing their night and/or weekend coverage to teleradiology companies. This means that the real boost of teleradiology has not yet taken place in Europe [17, 18].

In Europe, the deployment of teleradiology activities is closely associated to the distribution of PACS systems.

Table 7 Possible threats and dangers of teleradiology outsourcing (the highest percentages are in bold)

\begin{tabular}{|c|c|c|c|c|c|c|c|}
\hline Answer options & $\begin{array}{l}\text { Strongly } \\
\text { disagree }\end{array}$ & Disagree & Neutral & Agree & $\begin{array}{l}\text { Strongly } \\
\text { agree }\end{array}$ & $\begin{array}{l}\text { No } \\
\text { opinion }\end{array}$ & $\begin{array}{l}\text { Rating } \\
\text { average }\end{array}$ \\
\hline $\begin{array}{l}\text { Radiologists could lose control of their } \\
\text { business }\end{array}$ & $4 \%$ & $13 \%$ & $18 \%$ & $37 \%$ & $24 \%$ & $5 \%$ & 3.66 \\
\hline $\begin{array}{l}\text { Instability of jobs and/or income for } \\
\text { radiologists }\end{array}$ & $5 \%$ & $11 \%$ & $31 \%$ & $29 \%$ & $20 \%$ & $4 \%$ & 3.50 \\
\hline Loss of quality radiological reports & $4 \%$ & $20 \%$ & $19 \%$ & $40 \%$ & $14 \%$ & $3 \%$ & 3.42 \\
\hline Danger of missing urgent pathology & $4 \%$ & $22 \%$ & $21 \%$ & $38 \%$ & $13 \%$ & $2 \%$ & 3.36 \\
\hline Loss of quality medical care for patient & $5 \%$ & $23 \%$ & $22 \%$ & $31 \%$ & $17 \%$ & $2 \%$ & 3.34 \\
\hline Negative effect on training of residents & $4 \%$ & $25 \%$ & $20 \%$ & $35 \%$ & $13 \%$ & $4 \%$ & 3.28 \\
\hline Loss of radiological skills & $7 \%$ & $29 \%$ & $28 \%$ & $25 \%$ & $9 \%$ & $2 \%$ & 3.02 \\
\hline
\end{tabular}


PACS can be considered as the basis of teleradiology [2, 16]. Unfortunately there is still an uneven distribution of PACS throughout Europe, which leads to significant differences between countries regarding the usage of teleradiology. According to the e-Health Benchmarking III report of the European Commission, PACS availability is highest in Northern Europe, particularly in the Nordic countries and Baltic States (almost $100 \%$ ), closely followed by countries such as The Netherlands (97\%), Belgium (96\%) and the UK (95\%). High availability rates can also be found in Austria, Portugal and Spain. In France and Greece, however, only a quarter of the hospitals have a PACS on site. On average, approximately three-quarters of all hospitals have stand-alone PACS, but in the UK and Nordic countries, PACS is part of regional or national networks in most cases [4]. The availability of regional and national networks greatly facilitates the usage of teleradiology allowing a more efficient working process. These networks can be used for simple linear distribution of image data as well as for more sophisticated dynamic sharing of workflow, both within the organisation and across organisations (between other networked hospitals in the region and even across country borders). So-called "many-to-many" connections can be established, in which the connected centres can interact with each other through a common platform. Several online "market-place" models have been developed, using this many-to-many type of platform, both in the EU and in the USA. Some of the newer platforms even allow online procurement and contracting between different parties linked to the network [3, 19-22]. In Canada, a collaborative network platform is being deployed using a platform allowing dynamic context-aware workflow management and quality assessment [23]. One of the main advantages of these many-to-many platforms is the possibility to set-up online multidisciplinary meetings between the networked institutions, which facilitates the communication of results with the referring clinicians, and offers a possibility to add value to the radiological report [21]. The validity of these advanced teleradiology platforms and tools still needs to be established on a larger scale.

The advantages of using teleradiology are apparent to most participants of the survey; the majority perceive teleradiology's main advantage as being a tool to enhance collaboration between peers. The ability to electronically distribute imaging studies in order to organise the radiologists' work more efficiently is also highly appreciated. The scarce availability of radiologists and subspecialty radiology knowledge (mainly in smaller hospitals) in some countries is the main reason for outsourcing images to external parties. This is also believed to be one of the main reasons for the consolidation of teleradiology as a health service, with a distinct potential for increased importance in the future. Other advantages for using teleradiology include improved patient outcomes based on timely access to skilled services, increased efficiency and productivity of radiology team members, reduced costs and improved access to care in rural and underserved areas. Teleradiology can also be used to supplement coverage on evenings and weekends, and to fillin for unexpected absences [24]. The demand for teleradiology services is currently the greatest in the UK and Germany, corresponding well with the relative shortage of radiologists in those countries (Fig. 1). This is presumably one of the principal reasons for the extensive usage of teleradiology services in both these countries. In the UK, both national and international providers are able to provide teleradiology services [7]. In Germany these services are still limited to nights, weekends and vacations, although the German regulations allow an expansion under certain circumstances [25]. However, Germany prohibits interpretation of images outside of the country [26]. In 2010, the market size of teleradiology was estimated at US $\$ 184$ million, with more than half of the revenues coming from the UK and Germany [27].

The growing cost of healthcare throughout Europe has put e-Health high on the political agenda: the "Europe 2020 vision" is opening the way for e-Health services as e-Health is believed to have the potential to reduce public expenditure on healthcare [28]. Since teleradiology may also contribute to a more cost-effective healthcare system, it is likely to become an integral part of healthcare delivery across Europe [16, 25]. Our survey captured some fears relating to the pricing issue, which might become a predominant decision factor causing insurance companies and hospital directors to outsource images in order to make advantage of price and wage fluctuations nationally and internationally (in lower-wage countries). This fear is also reflected in the survey results, showing a majority of respondents consider teleradiology outsourcing as a potential threat for the radiologists' businesses and incomes (Table 7). It is also feared that this situation, in which radiology is reduced to a tradable "commodity", might lead to an additional risk of reduced quality of radiological services and patient care: in our survey almost half of all participants perceive this to be closely associated with a reduced quality of patient care [29].

Many perceive that teleradiology outsourcing is associated with potential poor-quality reporting and with insufficient quality assurance $[8,17]$. Several reasons contributing to this vision are mentioned in the literature, among them the statement that radiologists conducting teleradiology services have little or no contact with referring physicians and thus have little or no access to other relevant patientrelated information [17]. It has been stated that PACS and teleradiology have diminished the immediate contact between radiologists and patients, by creating the alleged "invisible radiologist" [21, 30]. Results from this survey 
Fig. 1 The numbers in this table represent the number of inhabitants per radiologist for each corresponding EU member state (figures include residents in training) [26]

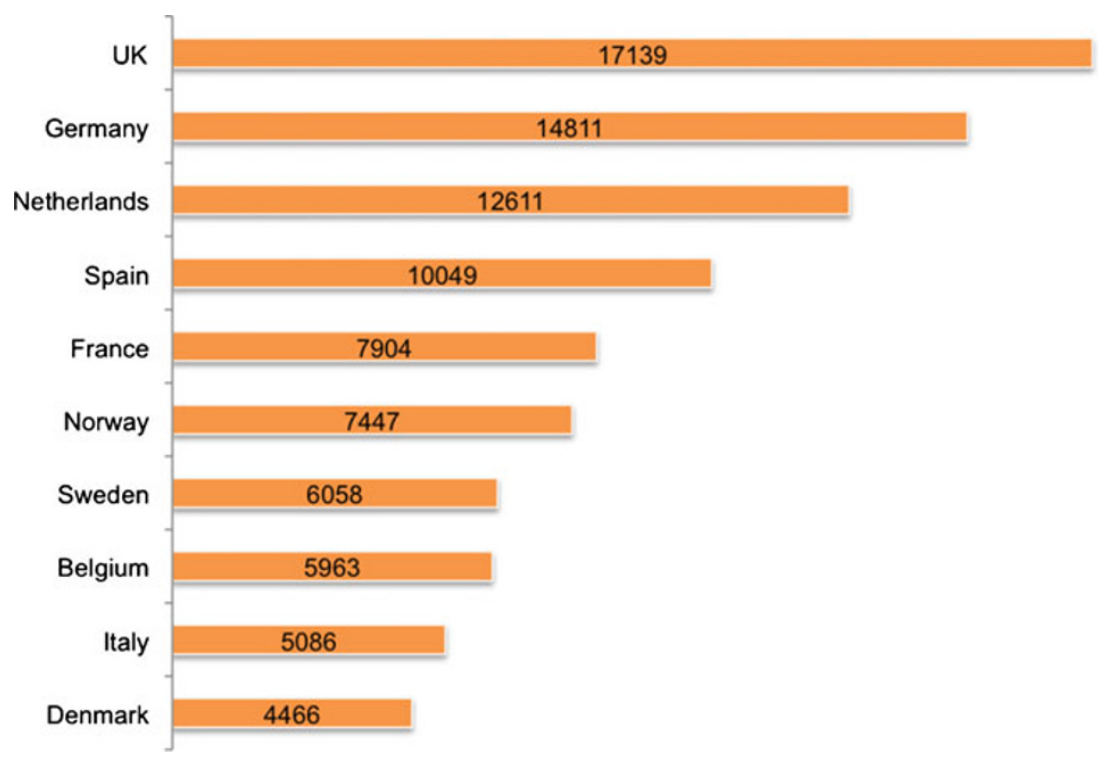

concur with these statements (Table 6). Insufficient access to relevant clinical information and/or priors (previous imaging studies) is considered to be the most important disadvantage of teleradiology outsourcing, followed by the lack of communication with the teleradiologist (so-called clinicoradiological communication). More than half of the participants fear a lower quality of reports, in addition to the significant potential danger that lies in the inability to communicate urgent findings in a timely manner (Table 7).

Obviously, in order to guarantee quality of care, all basic components that need to be addressed in an interorganisational setting (i.e. quality and trust, interoperability, identification, security, legal issues) also apply for crossborder teleradiology services. Semantic interoperability (problems related to differences in language) is certainly one of the factors limiting the implementation of crossborder services. Structured reporting is often mentioned as one of the possible solutions to overcome linguistic problems [3, 31]. There is a need for reinforcement at a European level to provide uniform regulations for registration, accreditation and revalidation. In addition some legal issues, mainly regarding liability, and issues related to patient privacy and patient safety, as yet remain unsolved [21]. This legal uncertainty is undoubtedly one of the main reasons for the rather modest implementation of telemedicine and teleradiology solutions in Europe. For example, it should be clear for patients if the radiologist providing the services is properly licensed and accredited, and also in which country the liability of the radiologist is to be addressed (country where patient is examined or country of residence of the radiologist). Another example is the fact that in some EU countries teleradiology is not defined as a medical act, leading to the possibility that some providers would offer diagnostic readings performed by non-medically trained individuals [21].
There is also a demand for further harmonisation of legislation regarding the processing of health data in cross-border healthcare services: a European directive is required to further guarantee the safety of patients. The ESR has published several documents in which they have expressed their vision and concerns about teleradiology and have also provided guidelines and recommendations for the development and use of teleradiology services within the EU [1, 32-34].

From this survey it also becomes clear that European radiologists are supporting the development of a European quality assurance system. In the ESR White Paper about Teleradiology (2006) it is stipulated that clinical auditing of teleradiology service is essential [1]. However, additional efforts should be made in order to implement an international quality framework, safeguarding the delivery of highquality teleradiology services on a pan-European level. The ESR has already recognised the need for creating standardised European training curricula, emphasising that it is essential that (international) teleradiology services should primarily be developed in the best interest of patient care and not as a cost-cutting measure which may jeopardise patient safety and the standards of healthcare. A new European Commission staff working paper offering clarifications regarding these issues is expected to be published in December 2012 (J. Schillebeeckx, personal communication, October 2012).

From a technical point of view the survey confirms that DICOM is the most widely used format for transmission of teleradiology data. This correlates with the findings of the Swiss teleradiology study [16]. The various teleradiology applications that are used within Europe have many different technical characteristics. In Germany, a large teleradiology network has been created based upon DICOM-email as the accepted standard [15, 35]. Other more recently 
developed teleradiology platforms are conceived as webbased management systems. Their development is focused on transferring images from PACS to PACS and they are relatively simple to implement [16]. However, there is still a considerable amount of hesitancy in implementing teleradiology in daily practice throughout the radiology and healthcare community for technical or IT-related reasons, as also appears from this survey (more than $20 \%$ ) [21].

Finally, a number of financial issues related to teleradiology are mentioned in the survey, such as the need to create a specific reimbursement system for teleradiology services, both for patients and for radiologists. The member states of the EU have responsibility for organising, providing and funding healthcare (so-called subsidiarity principle). The existing differences between the healthcare systems in the European countries are a major factor inhibiting a more rapid deployment of cross-border teleradiology services and are also responsible for the current differences in usage of teleradiology services [21]. In order to promote nationwide collaboration between radiologists, it would be desirable to make use of a uniform platform facilitating automated invoicing between all involved parties, as also reflected in the Swiss survey [16]. The financing of second opinions among peers (in a business-to-business concept) is still not regulated in most countries. In some countries where specific reimbursement of these services is lacking, a financial agreement needs to be made between the parties involved, the so-called "feeder" (radiologist requesting a second opinion) and "reader" (the radiologist providing one) [6]. Currently, in most situations the "readers" are more or less obliged to deliver these additional services on a voluntary basis. On the other hand, the "feeders" may show a "reluctance" to (structurally) outsource images to an "expert" charging for his/her reading services, without certainty of additional coverage from the patient's insurance company. According to the Swiss survey, the majority of radiologists claimed that insurance companies should pay for the cost of teleradiology [16]. An emerging model is based upon the usage of a commercial teleradiology network offering a win-win model in which both "feeders" and "readers" receive part of the remuneration that is generated for each study. In conclusion, it would be highly desirable if a viable financial model could be put in place supporting the remuneration of expert opinion services among peers. It is highly likely that this would be an incentive to intensify collaboration between peers, improving the overall quality of radiology services in the context of an increasing need for subspecialty advise, as is also reflected in our survey.

\section{Future}

European radiologists have an overwhelmingly positive opinion regarding the future of teleradiology, while also expressing a need for further standardisation (in training and quality assessment), providing both legal regulations and an adequate reimbursement system. In our opinion the latter is rather unlikely to occur on a pan-European scale, since the organisation of healthcare remains the sovereign responsibility of the EU member states (subsidiarity principle). Both the shortage in radiologists in several member states and the growing need for sub-specialisation are the principal reasons for the continued usage of teleradiology. The ability to discuss cases with experts or to obtain second/ expert opinions is one of the most attractive features of teleradiology. According to our findings, we foresee an interesting future in which collaborative networks will be increasingly used for diagnostic purposes, workflow management, quality assurance and even training purposes. In the long-term, the presence of teleradiology networks will fundamentally change radiology. Smaller radiology units will concentrate on daily business and fast reporting. Larger units also providing academic teaching can use these networks to offer specialised reading services [25]. We predict that due to the "online" presence of knowledge and expertise a self-organisation of these networks might result in new types of "virtual" radiology groups (expert groups) or in very large radiology groups providing services for a number of hospitals. This phenomenon of so-called consolidation is already taking place in the USA [38].

\section{Limitations of the survey}

Regarding the demographics of the participants, it is surprising that, in the absence of a selection bias, we did not obtain a well-balanced demographic set. The largest group of participants came from Austria and Belgium, together representing $44 \%$ of the total number of respondents. One explanation is to take into account some predetermined bias inherent to the response and collaboration of the representatives of the national radiological societies whom we contacted, since they were responsible for promoting participation to this survey among their members. An additional bias is possibly caused by the lack of recent updates of the contact list of ESR-affiliated radiological societies [10], used for contacting the national society representatives. A third bias is likely to be caused by the disparity of PACS distribution in Europe and by the existing differences between healthcare systems, creating a situation in which the usage of teleradiology is "encouraged" in one country and "discouraged" in another. It is not unlikely that these differences have influenced the participation degree of some countries. Additional large-scale studies, including a more geographically diverse sample, should be performed to further analyse this.

In addition, the survey has not included questions about the international IHE standards and profiles to support 
sharing of medical examinations, such as XDS-I (CrossEnterprise Document Sharing for Imaging). Further implementation of standards will facilitate the sharing and integration of patient-related information and images between different hospitals. In future studies and surveys, analysis of the usage of these new developments should be included.

We conclude that the wide adoption of PACS has paved the way for teleradiology in Europe. The ease of transmitting radiology images has led to the adoption of teleradiology as a viable and sustainable form of telemedicine in several European countries. Despite these developments, which mainly occur in countries with a high concentration of networked PACS, the growth in usage of teleradiology outsourcing in Europe in general is at a much slower pace in comparison to the United States. Currently the legal complexity regarding delivery of cross-border services on a European level is an important factor contributing to this delay; more clarity is expected in the near future. Several issues related to processing of health data, language (semantic interoperability), reimbursement and standardisation of training remain to be solved. For a European collaborative teleradiology model to succeed, the most crucial challenges are: implementation of a solid quality assurance system, seamless integration with electronic patient records, solutions to assure the quality and increase the value of radiology reports and solutions to improve communication with (locally) referring clinicians. It needs to be emphasised that acceptance and approval of teleradiology is not only required from the radiology community but also from referring physicians and their patients who are ultimately the consumers of the radiology community's productivity [36]. The most crucial question that needs to be asked is: "What will the patient think about this?".

Acknowledgments The authors wish to thank Dr. Jan Schillebeeckx for his critical appraisal of this paper.

Open Access This article is distributed under the terms of the Creative Commons Attribution License which permits any use, distribution, and reproduction in any medium, provided the original author(s) and the source are credited.

\section{References}

1. ESR (2006) VII Telerad white paper. Available via http:// www.myesr.org. Accessed 14 Oct 2011

2. Barneveld Binkhuysen FH, Ranschaert ER (2011) Teleradiology: evolution and concepts. Eur J Radiol 78:205-209. doi:10.1016/ j.ejrad.2010.08.027

3. Ross P, Sepper R, Pohjonen H (2010) Cross-border teleradiology - experience from two international teleradiology projects. Eur $\mathrm{J}$ Radiol 73:20-25. doi:10.1016/j.ejrad.2009.10.016

4. Deloitte \& Ipsos Belgium (2011) eHealth Benchmarking III SMART 2009/0022 Final Report. 1-274. Available via http:// ec.europa.eu/information_society/eeurope/i2010/docs/ benchmarking/ehealth_benchmarking_3_final_report.pdf. Accessed 23 Jan 2012

5. Benjamin M, Aradi Y, Shreiber R (2010) From shared data to sharing workflow: Merging PACS and teleradiology. Eur J Radiol 73:3-9. doi:10.1016/j.ejrad.2009.10.014

6. Mun SK, Tohme WG, Platenberg RC, Choi I (2005) Teleradiology and emerging business models. J Telemed Telecare 11:271-275. doi: $10.1258 / 1357633054893373$

7. European Society of Radiology 2009 (2010) The future role of radiology in healthcare. Insights Imaging 1:2-11. doi:10.1007/ s13244-009-0007-x

8. Dixon AK, FitzGerald R (2008) Outsourcing and teleradiology: potential benefits, risks and solutions from a UK/European perspective. J Am Coll Radiol 5:12-18. doi:10.1016/j.jacr. 2007.09.010

9. SurveyMonkey web-based survey tool. Available via https:// www.surveymonkey.com. Accessed Sept 2011

10. European Society of Radiologist "Highlights". Available via http:// www.myesr.org. Accessed Sept 2011

11. ESR Facebook page. Available via http://www.facebook.com/ myESR. Accessed Sept. 2011

12. Twitter website. Available via http://twitter.com/myESR. Accessed Sept. 2011

13. LinkedIn website. Available via http://www.linkedin.com. Accessed Sept. 2011

14. Flick U (2009) An introduction to qualitative research. Sage Publications, London

15. Weisser G, Walz M, Ruggiero S, Kämmerer M, Schröter A, Runa A, Mildenberger P, Engelmann U (2006) Standardization of teleradiology using Dicom e-mail: recommendations of the German Radiology Society. Eur Radiol 16:753-758. doi:10.1007/s00330005-0019-y

16. Lienemann B, Hodler J, Luetolf M, Pfirrmann CWA (2005) Swiss teleradiology survey: present situation and future trends. Eur Radiol 15:2157-2162. doi:10.1007/s00330-005-2764-3

17. Levin DC, Rao VM (2011) Outsourcing to teleradiology companies: bad for radiology, bad for radiologists. J Am Coll Radiol 8:104-108. doi:10.1016/j.jacr.2011.05.002

18. Ross P (2011, September) Pros and cons of international teleradiology services. Presentation held at MIR annual scientific meeting, Nice. Available via http://bit.ly/KMCxfj. Accessed 07 Oct 2011

19. Ross P (2011) Data sharing shared workflow medical imaging. Doctoral dissertation, Tallinn University of Technology, Talinn. ISBN: 978-9949-23-221-5

20. Ross P, Pohjonen H (2011) Images crossing borders: image and workflow sharing on multiple levels. Insights Imaging 2:141-148. doi:10.1007/s13244-010-0059-y

21. Pohjonen H (2010) Changing the European healthcare IT procurement market. Eur J Radiol 73:1-2. doi:10.1016/j.ejrad.2009.10.013

22. Dimmick S, Ignatova K (2006) The diffusion of a medical innovation: where teleradiology is and where it is going. J Telemed Telecare 12(Suppl 2):S51-S58. doi:10.1258/135763306778393090

23. Krestin G (2010) Commoditization in Radiology: threat or opportunity? Radiology. doi:10.1148/radiol.10100144

24. Rosenberg C, Langner S, Rosenberg B, Hosten N (2011) Medizinische und rechtliche Aspekte der Teleradiologie in Deutschland. Rofo 183:804-811. doi:10.1055/s-0031-1273220

25. Hotoppf M (2011) Teleradiology — a small business having a big impact Healthcare Europa. Available via http://www.healthcareeuropa. com/articles/privateteleradiologyeurope. Accessed Nov 2011

26. Kamalasekar S (2011) Teleradiology —an integral part of eHealth agenda in Europe. Available via http://www.frost.com/prod/ servlet/market-insight-top.pag?docid=236792794. Accessed 02 Jul 2011

27. Report on the public consultation on eHealth Action Plan 2012-2020. Available via: http://ec.europa.eu/information_society/ 
activities/health/docs/policy/ehap2012public-consult-report.pdf. Accessed 18 Mar 2012

28. Glazer GM, Ruiz-Wibbelsmann JA (2011) The invisible radiologist. Radiology 258:18-22. doi:1148/radiol.10101447

29. Boland G (2012, September) Teleradiology, how do we protect ourselves? Presentation held at MIR annual scientific meeting, London. Available via http://bit.ly/R4EHIn Accessed 13 Oct 2012

30. Bosmans J (2011) The Radiology Report, from prose to structured reporting and back again? Doctoral dissertation, University of Antwerp, Antwerp. ISBN 978-9-057283-39-0

31. ESR (2011) ESR response to consultation on the eHealth Action Plan (eHAP) Available via http://alliance-for-mri.org/html/img/ pool/eHealth_Action_plan_ESR_Response_final.pdf. Accessed 14 Oct 2012

32. ESR (2008) Response of ESR to communication on telemedicine COM 689 Available via http://www.myesr.org/cms/website.php? id=/en/eu_affairs/ec_communication_on_telemedicine/esr.htm. Accessed 01 Jan 2009

33. ESR (2011) ESR response to consultation on the eHealth Action Plan (eHAP) Available via http://www.myesr.org/html/img/pool/eHealth_ Action plan ESR Response final.pdf Accessed 14 Oct 2011

34. Weisser G, Engelmann U, Ruggiero S, Runa A, Schröter A, Baur S, Walz M (2007) Teleradiology applications with DICOM-e-mail. Eur Radiol 17:1331-1340. doi:10.1007/s00330-006-0450-8

35. Lester N, Durazzo T, Kaye A, Ahl M, Forman HP (2007) Referring physicians' attitudes toward international interpretation of teleradiology images. AJR Am J Roentgenol 188:W1-W8. doi:10.2214/ AJR.05.1303

36. Myanard I (2012) Orchestration of multi-site, cross-PACS Workflows. Presentation held at MIR annual scientific meeting, Milan

37. ESR Science Report. Available via http://bit.ly/M9pbKc. Accessed Sept 2011 